\title{
Hemorrhagic Nonpurulent Conjunctivitis in MIS-C
}

\author{
Suresh Kumar Angurana ${ }^{1}$ (D) Ajay Kumar ${ }^{1} \cdot$ Thakkar Malav $^{1}$ \\ Received: 11 January 2021 / Accepted: 12 April 2021 / Published online: 20 May 2021 \\ (C) Dr. K C Chaudhuri Foundation 2021
}

Three male children (5-8 y) presented with 5-7 d history of fever, abdominal pain, vomiting, rash, and redness of eyes. Examination revealed features of shock and respiratory distress, macular erythematous rash, periorbital puffiness, and nonpurulent conjunctivitis with subconjunctival hemorrhages (Fig. 1). All had negative severe acute respiratory syndrome coronavirus 2 (SARS-CoV-2) reverse transcription polymerase chain reaction (RT-PCR). Cases 1 and 3 had positive SARS-CoV-2 antibody, and case 2 had contact with coronavirus disease 2019 (COVID-19) patient. All had neutrophilic leucocytosis, lymphopenia, and thrombocytopenia; and elevated C-reactive protein (CRP), procalcitonin, d-dimer, fibrinogen, ferritin, and pro-BNP. Echocardiography revealed low ejection fraction (40\%-50\%) in all and coronary artery dilatation in two cases. The diagnosis of multisystem inflammatory syndrome in children (MIS-C) was considered and treatment included mechanical ventilation (noninvasive in 2 and invasive in 1), fluid boluses, vasoactive support, methylprednisolone $(10 \mathrm{mg} / \mathrm{kg} / \mathrm{d}$ for $3 \mathrm{~d})$ and intravenous immunoglobulin (IVIG) $(2 \mathrm{~g} / \mathrm{kg})$, and aspirin $(3 \mathrm{mg} / \mathrm{kg} / \mathrm{d})$. All cases improved and were discharged after 5 to $7 \mathrm{~d}$ on oral steroids and aspirin, which were stopped over the next 4-6 wk.

The conjunctivitis is documented in around $40 \%-56 \%$ children with MIS-C [1-3]. Eye manifestations in the three cases with MIS-C were labelled as hemorrhagic nonpurulent conjunctivitis and this finding, described for the first time, can be an important clue to the diagnosis of MIS-C. It took 2-3 wk for hemorrhagic nonpurulent conjunctivitis to resolve. The authors hypothesize that the causes for hemorrhagic nonpurulent conjunctivitis are SARS-CoV-2-induced endothelial cell damage and necrosis or vasculitis of conjunctival vasculature.

Suresh Kumar Angurana

sureshangurana@gmail.com

1 Division of Pediatric Critical Care, Department of Pediatrics, Advanced Pediatrics Centre, Postgraduate Institute of Medical Education and Research (PGIMER), Chandigarh 160012, India 
Fig. 1 Nonpurulent conjunctivitis with subconjunctival

hemorrhages in case 1 (a) case 2 (b and $\mathbf{c}$ ) and case 3 (d and e)
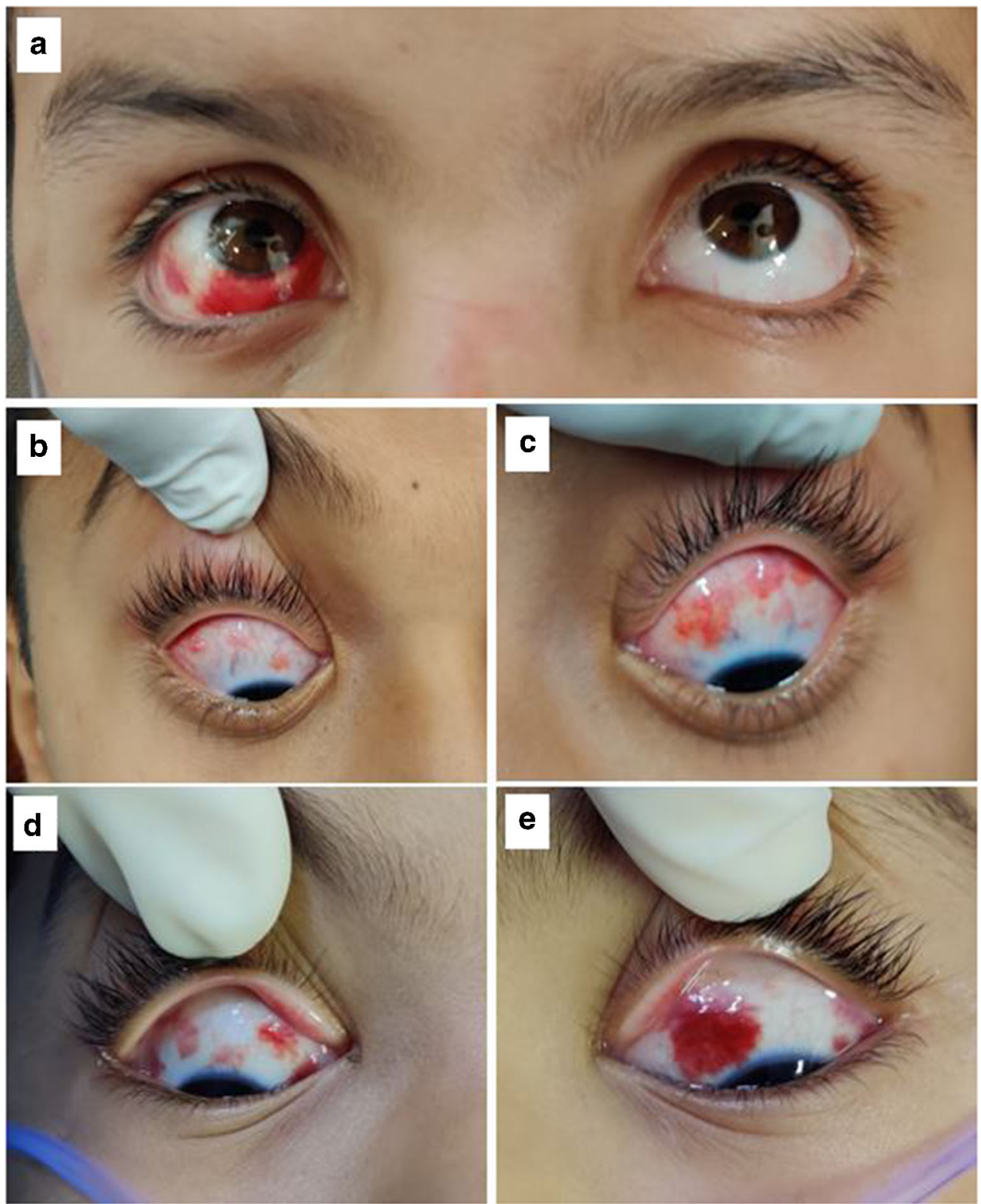

\section{Declarations}

\section{Conflict of Interest None.}

\section{References}

1. Williams V, Dash N, Suthar R, et al. Clinicolaboratory profile, treatment, intensive care needs, and outcome of pediatric inflammatory multisystem syndrome temporally associated with SARS-CoV-2: a systematic review and meta-analysis. J Pediatr Intensive Care. 2020 https://doi.org/10.1055/5-0040-1719173.

2. Dufort EM, Koumans EH, Chow EJ, et al. Multisystem inflammatory syndrome in children in New York state. N Engl J Med. 2020;383:347-58.

3. Godfred-Cato S, Bryant B, Leung J, et al. COVID-19-associated multisystem inflammatory syndrome in children - United States, march-july 2020. MMWR Morb Mortal Wkly Rep. 2020;69:107480.

Publisher's Note Springer Nature remains neutral with regard to jurisdictional claims in published maps and institutional affiliations. 